\title{
AÇÃO ANTAGÔNICA DE RIZOBACTÉRIAS CONTRA PHYTOPHTHORA PARASITICA E P. CITROPHTHORA E SEU EFEITO NO DESENVOLVIMENTO DE PLÂNTULAS DE CITROS ${ }^{1}$
}

\author{
EDNA PEIXOTO DA ROCHA AMORIM² \& ITAMAR SOARES DE MELO ${ }^{3}$
}

\begin{abstract}
RESUMO - O antagonismo de Pseudomonas putida biovar A (C1-1B), P. putida biovar B (Santa Bárbara), P. fluorescens (C2-8C e RA2), Bacillus subtilis (OG e RC2) e Flavobacterium sp. (CIS/NA) contra Phytophthora parasitica e $P$. citrophthora, agentes da podridão radicular dos citros, foi avaliado através da inibição do crescimento micelial (cultura pareada) e redução na percentagem de infecção da doença em mudas de citros (tratamento de sementes com rizobactérias). Na seleção preliminar, 33 isolados bacterianos foram testados. Sementes de citros pré-germinadas foram tratadas por imersão nas suspensões das bactérias $\left(10^{9} \mathrm{ufc} / \mathrm{ml}\right)$, e plantadas em tubetes contendo solo natural infestado com o fitopatógeno (50 $\mathrm{ml} \mathrm{de} \mathrm{suspensão/} \mathrm{kg} \mathrm{de} \mathrm{solo).} \mathrm{A} \mathrm{avaliação} \mathrm{da} \mathrm{percentagem} \mathrm{de}$ infecção foi efetuada após 15 dias. In vitro, os isolados bacterianos RC2, OG, CIS/NA e C1-1B foram os mais ativos inibidores do crescimento micelial de Phytophthora. Em condições de casa de vegetação, todos os isolados proporcionaram redução na percentagem de infecção da doença em todos os ensaios realizados. Promoção de crescimento de plantas foi verificada pela inoculação de plântulas com as linhagens OG, RC2, CiS/Na e C1-1B.
\end{abstract}

Termos para indexação: controle biológico, RPCP, podridão de raízes, citros

\section{ANTAGONISM OF RHIZOBACTERIA TO Phytophthora parasitica and P. citrophthora AND THE EFFECT ON DEVELOPMENT OF CITRUS SEEDLINGS}

\begin{abstract}
The antagonism of Pseudomonas putida biotype A (C1-1B), P. putida biotype B (Santa Bárbara), P. fluorescens (C2-8C and RA2), Bacillus subtilis (OG and RC2) and Flavobacterium sp. (CIS/NA) against Phytophthora parasitica and $P$. citrophthora, rhizobacteria, agent of root rot of Citrus sp., was evaluated by mycelial growth inhibition (paired culture) and reduction of disease percentage in seedlins (seeds treatment). In a preliminary screening, 33 bacteria isolates were tested. The citrus seeds were immersed in the bacteria suspensions $\left(10^{9} \mathrm{ufc} / \mathrm{ml}\right)$ and then sown in plastic tubes containing natural soil, previously infested with the pathogen at a concentration of $50 \mathrm{ml}$ of suspension $/ \mathrm{kg}$ of soil. The evaluation of the disease percentage was carried out after 15 days. In vitro, the isolates of bacteria RC2, OG, CIS/NA and C1-1B were the most effective inhibitors of the mycelial growh of Phytophthora. In greenhouse conditions all the isolates reduced the disease percentage. Beneficial effects were obtained with the isolates OG, RC2, $\mathrm{CiS} / \mathrm{Na}$ and $\mathrm{C} 1-1 \mathrm{~B}$ in relation to plant growth.
\end{abstract}

Index terms: Biological control, PGPR, root rot, Citrus

A podridão radicular dos citros (Citrus spp.), causada por Phytophthora parasitica (Dastur) Waterhouse e $P$. citrophthora (Smith \& Smith) Leon., é uma doença que pode provocar perdas significativas em viveiros de todas as regiões citrícolas. Segundo Feichtenberger (1990), o índice de contaminação em viveiros é alto e vem agravando-se diante da substituição de porta-enxertos, em virtude do aparecimento da tristeza (Citrus tristeza vírus) e do declínio (Xylella fastidiosa). A importância da sanidade em sementeiras é bastante significativa, mesmo quando o estoque da sementeira está destinado a áreas onde o patógeno já está presente. O controle da doença é maior se a planta estiver livre do patógeno no tempo do estabelecimento (Shea \& Broadbent, 1983).
Atualmente, o controle de Phytophthora spp., nos viveiros, ainda é feito com fumigantes (Feichtenberger, 1990). A microbiolização de sementes pode constituir uma opção potencial para o controle de fitopatógenos habitantes do solo, bem como para diminuir os problemas ambientais decorrentes do uso de produtos químicos no ambiente (Luz, 1993).

Microrganismos antagonistas do gênero Bacillus e Pseudomonas têm sido avaliados como um meio de controlar podridões radiculares causadas por Phytophthora spp. em eucalipto (Malajczuk et al., 1977) e soja (Sneh et al., 1977), pois, além de residirem no solo, rizoplano e filoplano, apresentam boas características para os estudos de controle biológico de doenças de plantas.

1 (Trabalho 181/2001). Recebido: 13/11/2001. Aceito para publicação: 02/05/2002. Parte da tese de doutorado da primeira autora FCA/UNESP, Botucatu, SP

2 CECA/UFAL, Departamento de Fitootecnia e Fitossanidade, Campus Delza Gitaí, km 104, km 85, 57.100-0000, Rio Largo, AL, 082261 -1676. E mail: epra@fapeal.br

3 EMBRAPA/CNPMA, Rodovia SP 340, Km 127,5, 13820-000, Jaguariúna,SP, 019 867-8700. Email: itamar@embrapa-cnpma.br 
Em vista disso, cogitou-se a possibilidade de utilização de bactérias antagonistas a $P$. parasitica e $P$. citrophthora na cultura dos citros, dado o potencial destas de colonizarem o sistema radicular e atuarem como uma barreira à penetração do patógeno. Este trabalho teve como objetivo verificar o potencial de rizobactérias no tratamento de plântulas de citros para o controle da podridão de raízes em viveiros.

Amostras de solo foram coletadas a partir de solo aderido às raízes provenientes de plantas de citros, localizadas em pomares com sintomas de Phytophthora spp. Suspensões de solo em solução salina $(0,85 \% \mathrm{NaCl})$, na proporção de $1 \mathrm{~g} / 9 \mathrm{ml}$, foram agitadas por um minuto em agitador vortex e por 20 segundos em ultra-som. Diluições em série foram feitas até $10^{-7}$ e alíquotas de $0,1 \mathrm{ml}$ das três últimas diluições foram plaqueadas em meio B de King (KMB). As culturas foram incubadas a $28^{\circ} \mathrm{C}$ por cinco dias, em câmara de crescimento, quando se procedeu a pulverização de uma suspensão de esporos de Phytophthora spp. sobre a superfície do meio onde as colônias de bactérias se desenvolviam. As culturas foram incubadas por mais sete dias a $28^{\circ} \mathrm{C}$, quando foram identificadas colônias de bactérias manifestando zonas de inibição aos fungos, as quais foram repicadas, purificadas em meio nutriente ágar (NA) e armazenadas a $5^{\circ} \mathrm{C}$.

Um isolado de $B$. subtilis (Ehrenb.) Cohn. e um de $P$. putida (Trev.) Mig., cedidos pela coleção de culturas de microrganismos do Laboratório de Fitopatologia da Embrapa Monitoramento Ambiental, foram incluídos aos ensaios, por serem antagônicos a diversos patógenos do solo.

As suspensões bacterianas foram preparadas a partir de culturas com 48 horas de crescimento em meio NA, sendo as células transferidas para tubos de ensaio com $10 \mathrm{ml} \mathrm{de} \mathrm{MgSO}_{4}$ $0.1 \mathrm{M}$ e mantidas sob agitação mecânica por 1 minuto. A concentração das suspensões foi determinada pela comparação com a escala de McFarland e ajustada para aproximadamente $10^{9}$ células/ml. A cada suspensão, foi adicionado o espalhante adesivo Tween 80 , na concentração de $0,05 \%$.

Foram utilizados um isolado de Phytophthora parasitica (P9) e um isolado de $P$. citrophthora (P45), provenientes do Instituto Biológico (SP). No preparo do inóculo, discos de cultura de Phytophthora em meio BDA foram repicados para placas com meio $\mathrm{V} 8-\mathrm{CaCO}_{3}$ e incubados por 10 dias a $28^{\circ} \mathrm{C}$, em regime de escuro contínuo, seguido da homogeneização com 200ml de água destilada.

Sete isolados de rizobactérias, selecionados em testes preliminares, foram submetidos a três ensaios contra $P$. parasitica e $P$. citrophthora em meio BDA (Batata-dextroseagár), colocando-se um disco de ágar de $5 \mathrm{~mm}$ de diâmetro com crescimento abundante de Phytophthora a $1,5 \mathrm{~cm}$ da borda da placa e na outra extremidade uma estria da bactéria selecionada. Após oito dias de incubação a $28^{\circ} \mathrm{C}$ e fotoperíodo de 12 horas, a redução do crescimento micelial foi medida.

$\mathrm{O}$ delineamento experimental foi inteiramente casualizado, em arranjo fatorial, com 14 tratamentos, constituídos pela combinação dos sete isolados bacterianos e os dois isolados de Phytophthora, e três repetições. As testemunhas foram constituídas por crescimento de discos de Phytophthora sem as bactérias.

Os dados originais do crescimento micelial de Phytophthora spp. foram submetidos a análise de variância, e as médias comparadas através do teste de Tukey, a $1 \%$ de probabilidade.

Sementes de limoeiro-Cravo (Citrus limonia Osbeck) foram desinfestadas em solução de hipoclorito de sódio $(\mathrm{NaClO}$ $0.7 \%$ ) por 5 minutos, lavadas em água corrente e, após a secagem por 24 horas, à temperatura ambiente, foram imersas nas suspensões bacterianas por 1 hora. As testemunhas consistiram de sementes desinfestadas e imersas em solução de $\mathrm{MgSO}_{4}$ $0.1 \mathrm{M}$ adicionada de Tween 80 , sem a presença de células bacterianas. Após a secagem por duas horas, as sementes foram semeadas em substrato não esterilizado, constituído por solo/areia/esterco de curral (2:1:1), infestado artificialmente com Phytophthora spp. através do tratamento com $50 \mathrm{ml}$ de suspensão/ kg de solo. Este ensaio foi repetido duas vezes.

Quinze dias após a germinação, foi feita a avaliação da percentagem de plântulas infectadas.

Utilizou-se um delineamento em blocos casualizados, com três repetições, sendo 32 plântulas por repetição. Os dados originais do número de plantas mortas foram transformados em $\sqrt{x+1}$, onde $\mathrm{x}=$ porcentagem de plantas infectadas, para efeito de análise estatística pelo teste de F, e as médias foram comparadas através do teste de Tukey, a $1 \%$ de probabilidade.

Tratamentos-controle somente com as rizobactérias foram feitos a fim de avaliar-se os efeitos das mesmas na promoção do crescimento de plântulas de limoeiro-Cravo. Avaliou-se a matéria seca da parte aérea e das raízes das plântulas, após dois meses de inoculação com as bactérias em substrato esterilizado.

Utilizou-se um delineamento em blocos casualizados, com três repetições, sendo 32 plântulas por repetição.

Antagonismo "in vitro" de rizobactérias contra Phytophthora

Dos trinta e três isolados bacterianos testados, sete apresentaram atividade antagônica à Phytophthora spp. em meio King's B, ou seja, 21,2\% foram capazes de inibir significativamente o crescimento micelial dos patógenos. Destacaram-se RC2, OG, C1S/Na e C1-1B (Tabela 1 ), sendo selecionados para os testes subseqüentes. Verificou-se que as bactérias introduzidas (OG e Santa Bárbara) mostraram atividade antagônica igual ou superior a C2-8C e RA2. Estes resultados indicam que as rizobactérias não apresentam especificidade de ação, o que permite a sua utilização para diferentes sistemas planta-hospedeiro.

O teste de antagonismo in vitro foi realizado em meio de KMB para detectar a produção de sideróforos. Acredita-se que pode ter ocorrido antagonismo tanto pela produção de sideróforos (competição por ferro) como pela produção de substâncias tóxicas (antibiose). Resultados semelhantes foram obtidos por Stein (1988), que verificou a inibição de fungos de solo por Pseudomonas fluorescentes, pelos mecanismos de antibiose e competição por ferro.

\section{Antagonismos "in vivo" de isolados de rizobactérias contra Phytophthora spp.}

Quando aplicados como tratamento de sementes, os isolados bacterianos diferiram significativamente entre si quanto à capacidade de reduzir a doença (Tabela 2). Os isolados OG, CiS/Na e C1-1B foram mais eficazes em controlar a doença, não diferindo significativamente dos isolados Sta. Bárbara e RC2.

Estes resultados levam-nos a crer que os isolados de rizobactérias dos citros são eficientes colonizadores de raízes,

Rev. Bras. Frutic., Jaboticabal - SP, v. 24, n. 2, p. 565-568, agosto 2002 


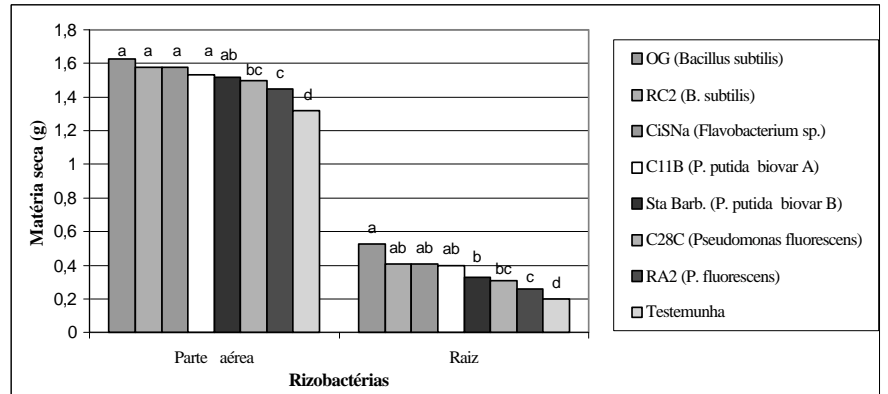

FIGURA 1 - Efeito do tratamento de sementes de citros com isolados de rizobactérias sobre desenvolvimento de plântulas de citros.

possivelmente pela capacidade de crescimento e/ou habilidade competitiva. Brown (1974) constatou que crescimento rápido e competição são algumas das características necessárias ao sucesso do estabelecimento na rizosfera.

Com relação às bactérias introduzidas nos experimentos, muitos trabalhos ressaltam o grande potencial de espécies de Bacillus no controle de patógenos do solo. Melo et al. (1995) constataram que a linhagem OG de B. subtilis isolada do rizoplano de feijoeiro, no município de Guaíra (SP), foi um potente antagonista contra alguns patógenos de raízes de feijão, como F. solani f. sp. phaseoli Kendrick \& Snyder, Rhizoctonia solani e Sclerotium rolfsii.

\section{Promoção de crescimento induzido pelas rizobactérias}

Com relação à promoção de crescimento, verificou-se que todos os tratamentos promoveram o crescimento das plântulas de citros, tanto para raiz como para parte aérea, quando comparados à testemunha (Figura 1). B. subtilis (OG e RC2), Flavobacterium sp. (CiSNA) e P. putida (C1-1B e Sta. Bárbara) proporcionaram melhores efeitos. Estes dados mostram que as rizobactérias estimulam o crescimento direto das plantas na ausência de patógenos (Luz, 1993).

Várias hipóteses têm sido aventadas no sentido de explicar a capacidade que possuem as rizobactérias de promover o crescimento das plantas. A maioria dos trabalhos relaciona essa capacidade à inibição e alteração da microbiota normal da rizosfera, fazendo com que a planta cresça com um sistema radicular sadio, seja por antibiose (Brisbane \& Rovira, 1988), seja ou pela competição por nutrientes, destacandose entre esses o ferro(Geels \& Schippers, 1983) e o carbono

TABELA 1 -Eficiência de isolados bacterianos na redução do crescimento micelial de Phytophthora parasitica e P. citrophtora.

\begin{tabular}{|c|c|c|}
\hline Tratamentos & Crescimento miceliano (cm) & $\%$ de inibição \\
\hline Testemunha* & 7,50 a $* *$ & 00,00 \\
\hline Sta. B árbara (P.putida biovar B ) & $4,85 \quad b$ & 35,33 \\
\hline C 2-8C (Pseudomonas fluorescens) & $4,58 \quad b$ & 38,93 \\
\hline R A 2 (P. fluorescens) & $4,55 \quad b$ & 39,33 \\
\hline C $1-1 \mathrm{~B} \quad(P . p u t i d a$ biovar A $)$ & $3,82 \quad \mathrm{c}$ & 49,06 \\
\hline $\mathrm{C}$ iS/N a (Flavobacterium sp.) & 3,65 & 51,70 \\
\hline $\mathrm{O} \mathrm{G}$ ( B acillus subtilis) & 3,63 & 51,60 \\
\hline RC2 (B. subtilis) & 3,55 & 52,66 \\
\hline
\end{tabular}

$\mathrm{CV}(\%)=5.87$

* Isolados de Phytophthora ( $\mathrm{P}_{45}$ e $\mathrm{P}_{9}$ não apresentaram diferença entre as médias de crescimento).

** Médias de três repetições. Médias seguidas com a mesma letra não diferem entre si, pelo teste de Tukey, a $1 \%$ de probabilidade.

TABELA 2 - Eficiência de isolados de rizobactérias no controle de Phytophthora parasitica e P. citrophthora. em plântulas de citros.

\begin{tabular}{|c|c|c|}
\hline Tratamento & $\%$ de Mortalidade & Controle \\
\hline $\begin{array}{l}\text { Testemunha } * \\
\text { RA2 (Pseudomonas fluorescens) } \\
\text { C2-8C (P. fluorescens) }\end{array}$ & $\begin{array}{l}77,7 \mathrm{a}^{* *} \\
44,3 \mathrm{ab} \\
22,2 \mathrm{~b}\end{array}$ & $\begin{array}{r}0,00 \\
43,00 \\
77,4.3\end{array}$ \\
\hline $\begin{array}{l}\text { Sta. Bárb. (P. putida biovar B) } \\
\text { RC2 (Bacillus subtilis) } \\
\text { C1S/Na (Flavobacterium sp.) } \\
\text { C1-1B (P. putida biovar A) } \\
\text { OG (B. subtilis }\end{array}$ & $\begin{array}{rr}11,1 & \mathrm{~cd} \\
11,1 & \mathrm{~cd} \\
0,0 & \mathrm{~d} \\
0,0 & \mathrm{~d} \\
0,0 & \mathrm{~d}\end{array}$ & $\begin{array}{c}85,72 \\
85,72 \\
100,00 \\
100,00 \\
100,00\end{array}$ \\
\hline
\end{tabular}

$\mathrm{CV}(\%)=\quad 28.28$

$* \mathrm{P}_{45}=P$. citrophthora $; \mathrm{P}_{9}=$ P. parasitica.

** Médias seguidas com a mesma letra não diferem entre si, pelo teste de Tukey, a 1\% de probabilidade. 
(Elad \& Chet, 1987). Os isolados Santa Bárbara e OG, que têm promovido o crescimento de plântulas de pepino e tomate ( Melo et al., 1995), comprovam, nesse trabalho, seu efeito benéfico na promoção do crescimento de plantas de citros.

Conclui-se que Pseudomonas putida, biovares A e B, Flavobacterium sp. e Bacillus. subtilis são capazes de controlar Phytophthora parasitica e P. citrophthora e promover o desenvolvimento de plântulas de citros.

\section{AGRADECIMENTOS}

Os autores agradecem à Dra. Dirce M. Yamaoka-Yano (Universidade Estadual de Campinas/Instituto de Biologia) e ao Dr. Pedro José Valarini (CNPMA/EMBRAPA), pela identificação dos isolados bacterianos testados

\section{REFERÊNCIAS BIBLIOGRÁFICAS}

BRISBANE, P.G.; ROVIRA, A.D. Mechanism of inhibition of Gaeumannomyces graminis var. tritici by fluorescent pseudomonads. Plant Pathology, Palo Alto, n. 37, p. 104 -111, 1988.

BROWN, M. E. Seed and root bacterization. Annual Review of Phytopathology, Palo Alto, n. 12, p. 181-221, 1974.

ELAD, Y.; CHET, I. Possible role of competition for nutrients in biocontrol of Pythium damping-off by bacteria. Phytopathology, St. Paul, n. 77, p. 190-5, 1987.

FEICHTENBERGER, E. Resistência de combinações varietais cítricas a fungos do gênero Phytophthora. In: INTERNATIONAL SEMINAR ON CITRUS ROOTSTOCKS, 2., 1990, Bebedouro. Anais... p. 233-42.

GEELS, F.P.; SCHIPPERS, B. Selection of antagonistic fluores- cent Pseudomonas spp. and their root colonization and persistence following treatment of seed potatoes. Phytopathology, St. Paul, n.. 73, p. 193-206, 1983.

LUZ, W. C. Microbiolização de sementes para o controle de doenças de plantas. Revisão Anual de Patologia de Plantas, Rio Grande do Sul, v.1.p. 33-77, 1993.

MALAJCZUK, N.; McCOMB, A. J.; PARKER, C. A. Infection by Phytophthora cinnamomi Rands of roots of Eucalyptus calophylla R. Br. and Eucalyptus marginata Donn. Australia Journal Botanic, Collingwood, n. 25, p. 483$500,1977$.

MELO, I. S.; VALARINE, P. J.; FAULL, J. L. Controle biológico de Fusarium solani f. sp. phaseoli por Bacillus subtilis isolado da rizosfera do feijoeiro. Fitopatologia brasileira, Brasília, n.20, p. 342, 1995.

SHEA, S. R.; BROADBENT, P. Developments in cultural and biological control of Phytophthora diseases. In: Erwin, D. C. (Coord.) Phytophthora, its biology, taxonomy, ecological and physiology.. Annual Phytopathology, Paris , n. 4, p. 33550,1983 .

SNEH, B.; HUMBLE, S. J.; LOCKWOOD, J. L. Parasitism of oospores of Phytophthora megaspermae var. sojae, P. cactorum, Pythium and Aphanomyces euteiches in soil by oomycetes, chytridiomycetes hyphomycetes, actinomycetes and bacteria. Phytopathology, St Paul, n. 67, p. 622-8, 1977.

STEIN, R. L. B. Efeito de Pseudomonas spp. fluorescentes no controle "in vitro" de fungos do solo e no desenvolvimento do tomateiro (Lycopersicon esculentum Mill). 1988. 176f, Dissertação (Mestrado em Fitossanidade), Universidade Federal Rural de Pernambuco, Recife, 1988. 